\title{
The ESP Instruction: A Study Based on the Pattern of Autonomous Inquiry
}

\author{
Jianfeng Zhang ${ }^{1}$ \\ ${ }^{1}$ College of Humanities and Foreign Languages, Xi' an University of Science and Technology, China \\ Correspondence: Jianfeng Zhang, College of Humanities and Foreign Languages, Xi'an University of \\ Science and Technology, Lintong District, Xi'an City, Shaanxi Province, 710600 China. Tel: \\ 86-135-722-536-26. E-mail: zhangjianfeng091024@126.com
}

The research is financed by Scientific Research Program Funded by Shaanxi Provincial Education Department (Program No. 12JK0297) and the Instructional Research Project of Xi'an University of Science and Technology (Program No. JG10044).

\author{
Received: December 19, 2012 Accepted: December 31, 2012 Online Published: February 1, 2013 \\ doi:10.5539/elt.v6n3p72 URL: http://dx.doi.org/10.5539/elt.v6n3p72
}

\begin{abstract}
Autonomous inquiry learning is a kind of learning model, which relies mainly on learners and emphasizes that learners should inquire knowledge actively; moreover, ESP, which emphasizes the combination of language learning and specific purposes learning, is a goal-oriented and well targeted instruction system. Therefore, ESP and autonomous inquiry can be mixed to construct a new model of instruction, which makes the learners explore and construct the knowledge as well as solving problems through acquired knowledge. The ability of autonomous learning will be strengthened. Meanwhile, English language teaching and professional skills can be mixed as well, so the performance of college English instruction can be improved significantly and the needs of national economic development and international communication can be met.
\end{abstract}

Keywords: ESP, autonomous inquiry, instructional model, model design

\section{Introduction}

The world has increasingly become more globalized and at the same time, more and more people are trying to use English in a growing number of occupational contexts. With the increasing acceptance, English dominates foreign-language curriculum in China and it is popular in the context of teaching language for specific purpose. In fact, English for specific purposes (ESP) is a goal-oriented and well targeted instruction system, which stresses the combination of English language learning and specific purposes of professional learning. It aims to meet learners-specific needs in the utilization of English for their specific fields of study (Benson, 2001), whereas autonomous inquiry learning is a kind of learning model, which relies mainly on learners and emphasizes that learners should inquire knowledge actively. Therefore, in this study, ESP and autonomous inquiry are mixed to construct a new model of instruction, which makes the learners explore and construct the knowledge as well as solving problems through acquired knowledge. The learners' ability of autonomous learning will be strengthened, so the performance of English language teaching can be improved significantly.

\section{Literature Review}

\subsection{English for Specific Purposes}

In recently years, English for specific purposes (ESP) has been a popular movement in language learning and teaching. The ESP began in 1950s and 1960s when there was an expansion of scientific, technical and economic activities on an international scale (Dudley-Evans \& St. John, 1998). ESP derives from the Register Theory of functional linguistics and it includes business English, financial \& economic English, legal English, tourism English etc. for specific or academic purposes. Therefore, ESP is not a simple curriculum; it requires English instructors to explore the curriculum, to re-design teaching plans and to implement ESP education (Askehave, 2001). Based on the theory of demands and needs of communication, the ideal ESP should meet learners' specific needs in the using of English for their specific professional 
fields of study; the contents of ESP instruction should correlate with the specific major or career; vocabulary, structure and discourse of ESP should adapt to the specific utilization of English so that ESP is totally different from the English for general purposes (EGP).

The teaching ESP started very early in China but it has developed so slowly. The theoretical basis and instructional experience are so weak and limited that the provision of ESP courses in universities of China is lack of ESP background among general English instructors (Chen, 2000). Generally speaking, in the real process of teaching, there are two major instructional models: one is the traditional teaching EGP. This approach leads to more emphasize on the vocabulary, grammar and syntax of components of English language learning, (Nurweni, 1999). No systematic ways are adopted to assist college students in noticing sufficiently professional knowledge as expected. Usually, the instructors resort to translating technical textbooks into Chinese sentence by sentence. So ESP learners do not see the need to read an original textbook in English. Another teaching model stresses the learning and acquisition of the professional skills or techniques. Eventually, the ESP instruction becomes bilingual teaching. These two models ignore learners' ability of autonomous learning and affect the improvement of communication; therefore, learning motivation is hard to be activated and the performance of teaching is ineffective. This kind of phenomenon is not unique to China, though. It seems to be very common through the world (Grabe \& Stoller, 1997).

In addition, nowadays ESP textbooks that are used in most universities are produced by their own teachers. Not only are the number of textbooks insufficient, but also the content is out of date, so that the teaching coverage is very narrow and teaching ESP cannot embody the latest tendency of a specific field (Robinson, 1991). Meanwhile, these textbooks lack definite instructional objectives and the systematicness and consistency of instructional content is not very apparent. Moreover, curriculums don't have corresponding courseware basically so that the using of ESP textbooks is relatively disorganized. The problems which exist in ESP instruction have hindered the development of ESP in China. Therefore, it is necessary and significant to construct a new model of ESP instruction which can fully focus on learner-centered and content-based approaches.

\subsection{The Theoretical Basis of Autonomous Inquiry}

The autonomous inquiry, which is mainly based on cognitive psychology, humanistic psychology and constructivism, is a generic skill that has the ability to detect gaps in knowledge itself and overcome them through critical reflection and choice of the best action to fill these gaps. Three levels are defined:

Level 1: participate and collaborate in the teamwork, once the objectives and responsibilities have been defined and a strategy has been collectively defined.

Level 2: help to strengthen the team, planning objectives, working efficiently and promoting the team communication, cohesion and distribution of tasks.

Level 3: lead and stimulate team works solving possible conflicts, appreciating the work done by others and evaluating the effectiveness of the team and the presentation of the results. (ICE. 2011b).

The National Science Education Standards of America defines the autonomous inquiry as "students must involve in inquiry-oriented investigations in which they interact with their teachers and peers. Students establish connections between their current knowledge of science and the scientific knowledge found in many sources; they apply science content to new questions; they engage in problem solving, planning, decision making, and group discussions; and they experience assessments that are consistent with an active approach to learning." (National research Council, 1996)

Autonomous inquiry learning is a scientific and systematic learning model, which relies mainly on learners and emphasizes that learners should inquire knowledge actively (Qian, 2002). Learners should fulfill inquiring tasks and master the relevant theories and draw a conclusion via reading, observing, experimenting, thinking and discussion. Through active inquiry and construction, learners dominate the cognitive process, which language knowledge is absorbed and internalized so that the ability of communication can be improved significantly and the dominant position of learners has been strengthened. Learners need to actively think about what to do and how to do instead of accepting read-made conclusions which instructors or books provide. In addition, autonomous inquiry learning has also an important role in e-learning because the distance courses and the semi-distance courses are designed following only the principles of the student autonomy.

Therefore, in this study, ESP and autonomous inquiry are attempted to be mixed in order to construct a novel context of language and professional learning, which can tap consciousness, autonomy and creativity 
of learners so that English learning motivations are able to be completely activated. Gradually, learners are no longer accepted knowledge passively and blindly. On the contrary, learners can predominate the process of cognition and knowledge construction.

\section{A Design of ESP under Autonomous Inquiry}

\subsection{Traditional ESP Instruction}

At present, the ESP instruction in China ignores learners' ability of autonomous learning. Instructors only utilize textbooks to input linguistic forms and the knowledge of a specific field. Generally speaking, instructors usually follow this pattern, which is shown in figure 1.

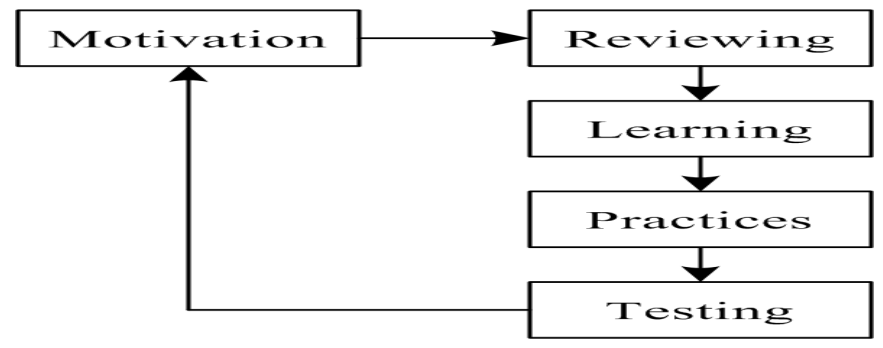

Figure 1. Traditional Teaching and Learning Model

Firstly, to activate learners' learning motivations, language samples are analyzed and explained deliberately by teachers. Then lessons which have been learned are reviewed again and the new one will be followed. With repeated practices and language testing, finally the language knowledge of a specific field is hoped to be acquired. In this teaching and learning model, however, instructors and learners are unable to interact well, so the performance of ESP instruction is usually ineffective.

\subsection{ESP under Autonomous Inquiry}

After the careful analysis of the features of ESP instruction and the reference of the traditional teaching and learning models in China, a new model of instruction, which is based on theories of cognitive psychology and constructivism, has been established. As a kind of instructional model, it should possess the generality and inclusiveness. In addition, this model should also be opened and it owns some distinct variables which have certain generative abilities. The model is shown in figure 2 .

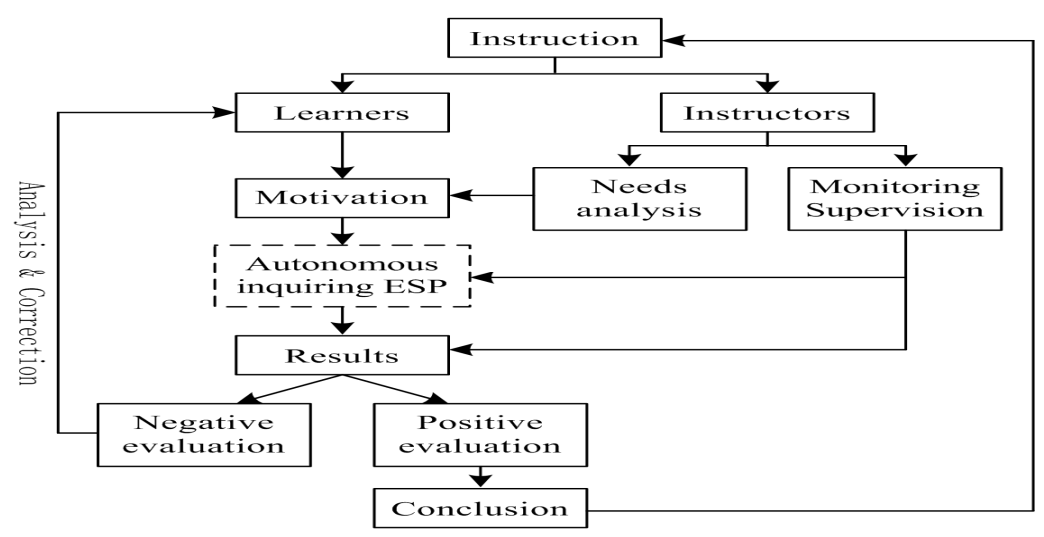

Figure 2. ESP under Autonomous Inquiry

Firstly, ESP instruction should be divided into two parts: instructors and learners. As the administrators and supervisors in the instructional activities, ESP instructors should carefully analyze the demands and needs of learners in a specific field so that the content of instruction can be involved in the learning tasks. Then, instructors need seriously screen and raise moderate questions which are valuable and logical. As inquiring tasks, these questions are posed in order to attract the attention of learners and to make them interested in the learning content to arouse their curiosity and stimulate motivations. Instructors, therefore, play a role of director in teaching ESP and their functions are not dropped but rose in that the preparing for curriculums is 
increased massively. Instructors have to carefully consider the content, teaching details, open discussion, time management and classroom organization etc. Usually, instructors should briefly introduce the phonetics, grammar, communicative functions and cultural backgrounds so the difficulties of language can be solved at the beginning of the curriculum. Moreover, they are expected to collect and list all valuable topics to enlighten learners' critical thinking and successfully stimulate motivation by deliberate-deigned brain storms and make good preparation for learners' autonomous inquiry.

Next, during the learner-oriented process of ESP under autonomous inquiry, learning teams should be distributed cautiously. The main purpose is to promote the development of learners' language expression ability, professional skills and cooperative capabilities. It is the key step that developing the cooperative inquiring tasks, drafting the reasonable plans, choosing the appropriate methods and starting the inquiring process is in ESP instruction.

Finally, ESP instructors must test and evaluate learners' achievements comprehensively. The evaluation should be divided into the positive and negative parts (Shee, 2008). If the evaluation is positive, that means the whole learning activities have completed. Learners have reached the requirements of the curriculum and they are able to use English in a specific field for meaningful communication and can solve some professional problems. Therefore, they should have higher demands and needs of learning so a new cycle of autonomous inquiry can begin. On the other hand, if the evaluation is negative, that means these activities are unable to finish successfully. Instructors should analyze and correct the existing problems. Inquiring tasks should be redesigned so that learners can start a new inquiry to achieve ultimate purposes of the course.

\subsection{A Flowchart of ESP under Autonomous Inquiry}

During the process of ESP instruction, with the directing of instructors, learners have completed the inquiring tasks via autonomous and collaborative learning. The flowchart can be seen in figure 3 .

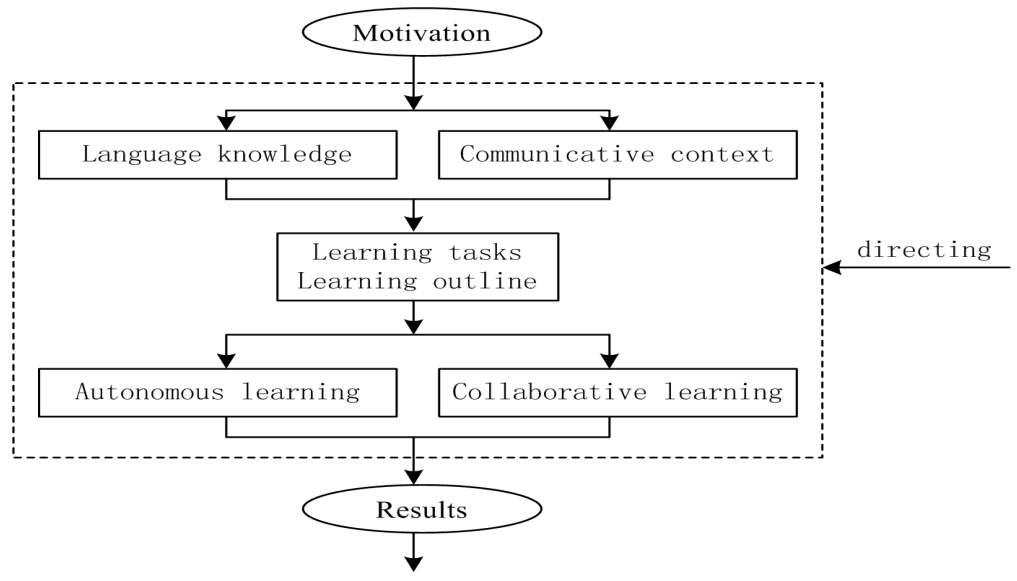

Figure 3. Flowchart of ESP under Autonomous Inquiry

ESP is a learner-centered curriculum where learners can actively and internally acquire specific knowledge with the directing and aiding of instructors. So after the learners' learning motivations have been stimulated successfully, what learners' needs are to obtain the basic knowledge of language and authentic communicative context. And then, learners should understand the learning tasks and actively construct the learning outline according to the specific targets of the curriculum. During the learning process, they should actively observe and think in order to form a leap and generate internal driving forces which can aid them to organize the information, to store the information and to fetch the information so that inquiring activities can be developed further.

Therefore, in the process of autonomous inquiry, learners can utilize Internet to help them complete inquiring tasks. Autonomous learning and collaborative learning are two major approaches that are so popular at present. In other words, compared with learners as the main part of the ESP curriculum, instructors are only directors and promoters. 
Generally speaking, in the module of autonomous learning, learners are allowed to fully use information from Internet, online resources, free courseware and simulation software that can imitate authentic language environment for them to inquire. However, some problems may occur and can't be effectively solved by autonomous learning so the collaborative learning is also very necessary. In the module of collaborative learning, learners share information and recourses to settle these problems. Nowadays, the reach of the Internet makes it possible to unite geographically-scattered learners in a virtual classroom. Methods such as BBS, ICQ, and MSN etc. will allow learners both to proceed at their own pace, and to intact with one another and their instructors so that all problems can be solved and the results of inquiring tasks are formed. As a whole, during those two learning methods, learners dominate the cognitive process by active inquiry, thinking and construction of English language knowledge and professional skills so that when they improve their language proficiency quickly, they gain knowledge of specific fields as well.

Finally, after a series of autonomous inquiry, learners need comb and summarize their information and materials so that results can be collected and conclusions will be drawn. Sometimes, different teams have different attitudes towards a same question, but they must express their views very clearly because those results will be discussed in the classroom.

In short, learners can continuously develop their abilities and potential in the ESP instruction which is under the pattern of autonomous inquiry. When they fulfill the current inquiring tasks, they are still faced with learning tasks independently and they need to improve themselves on end. If language learning and profession skills can mixed well under autonomous inquiry, the performance of ESP instruction will be improved and the effect of language learning will be strengthened as well.

\section{Conclusion}

The ESP instruction which is based on the pattern of autonomous inquiry has changed the traditional teaching models and has stimulated learners' learning motivations greatly in order to enhance their self-taught abilities, communicative abilities, logical and critical thinking. Because of the features of interdiscipline in ESP curriculum, it is unlikely and unpractical to set up a unified model. But in the long-run, the combination of ESP and autonomous inquiry can maximally mobilize learners' enthusiasm and cultivate their spirits of active learning and innovative learning. If the knowledge structure can be optimized and the good learning habits are able to be formed, learners will own lifelong benefits so it also helps to train diversified and interdisciplinary talents who can meet the needs of development of industrialized society.

However, because of the features of ESP and imbalance of regional distribution of educational resources, in the practical teaching process, the phenomena of coexistence of a variety of English instructional models will still exist in quite a long period time. In addition, an empirical evaluation of this theoretical model should follow this study.

\section{References}

Askehave, I., Swales, J. (2001). Genre identification and communicative purpose: a problem and a possible solution. Applied Linguistics, 22(2), 195-212. http://dx.doi.org/10.1093/applin/22.2.195

Benson, P. (2001). Teaching and researching autonomy in language learning. London: Longman.

Chambers, F. (1980). A re-evaluation of needs analysis in ESP. English for Specific Purposes Journal, 1(1), 25-33. http://dx.doi.org/10.1016/0272-2380(80)90007-4

Chen, T. Y. (2000). Self-training for ESP through action research. English for Specific Purposes, 19, 389-402. http://dx.doi.org/10.1016/S0889-4906(00)00008-9

Dudley-Evans, T., \& St. John, M. (1998). Developments in ESP: A multi-disciplinary approach. Cambridge: Cambridge University Press.

Grabe, W., \& Stoller, F. (1997). Reading and vocabulary development in a second language: a case study. In Coady, J., \& Huckin, T. (Eds.), Second Language Vocabulary Acquisition. Cambridge University Press, New York.

ICE. (2011b). Guia per desenvolupar les competències genèriques en el disseny de titulacions. Treball en equips. Barcelona: Universitat Politècnica de Catalunya. Institut de Ciències de l'Educaciô (ICE), Retrieved from http://www-ice.upc.edu/

National research Council. (1996). The National Science Education Standards. Washington D.C: National Academy Press. 
Nurweni, A., \& Read, J., (1999) The English vocabulary knowledge of Indonesian university students. English for Specific Purposes, 18, 161-175. http://dx.doi.org/10.1016/S0889-4906(98)00005-2

Qian, D., (2002). Investigating the relationship between vocabulary knowledge and academic reading performance: an assessment perspective. Language Learning, 52, 513-536. http://dx.doi.org/10.1111/1467-9922.00193

Robinson, P. C. (1991). ESP today: A practitioner's guide. Hemel Hempstead: Prentice Hall.

Shee, D. Y., \& Wang, Y-S. (2008). Multi-criteria evaluation of the web-based e-learning system: A methodology based on learner satisfaction and its applications. Computers \& Education, 50(3), 894-950. http://dx.doi.org/10.1016/j.compedu.2006.09.005 